\title{
Rate, Clinical Features, Safety Profile and Outcome of Intravenous Thrombolysis for Acute Ischemic Stroke in Patients With Negative Brain Imaging
}

\author{
Ashkan Mowla ${ }^{\mathrm{a}, \mathrm{e}}$, Haris Kamal ${ }^{\mathrm{b}}$, Sandhya Mehlac, \\ Peyman Shirani ${ }^{\mathrm{d}}$, Robert N. Sawyer ${ }^{\mathrm{c}}$
}

\section{To the Editor}

Intravenous (IV) recombinant tissue plasminogen activator (rtPA) is the only Food and Drug Administration (FDA)-approved pharmacological therapy for acute ischemic stroke (AIS) [1-8]. The exigent time demand for IV r-tPA administration in AIS may not give the necessary time for thorough evaluation in patients presenting with AIS symptoms. As a result, IV thrombolysis of transient ischemic attack (TIA) or conditions mimicking stroke but with a subsequent different diagnosis might occur. In addition, IV r-tPA may sufficiently resolve ischemia such that subsequent brain diffusion-weighted magnetic resonance imaging (DWI-MRI) is negative in some patients. It would be expected that brain computed tomography (CT) scan and the more sensitive DWI-MRI would be negative in all these cases [9-11]. We sought to determine the rate, clinical characteristics, safety profile and outcome of brain imaging-negative patients treated with IV r-tPA for AIS in our large volume comprehensive stroke center, Buffalo General Hospital, Buffalo, NY, USA.

We retrospectively reviewed the medical records and brain imaging of patients who received IV r-tPA for AIS within $4.5 \mathrm{~h}$ of symptom onset in a 9.4-year period at our center. A subset of patients with absence of acute infarct/ischemia on their follow-up brain imaging were identified. The 24-h MRI-DWI was available for the majorly of the patients $(90.1 \%)$. For those who had no fol-

Manuscript submitted May 17, 2020, accepted May 25, 2020

Published online June 3, 2020

${ }^{a}$ Division of Endovascular Neurosurgery, Department of Neurological Surgery, Keck School of Medicine, University of Southern California (USC), Los Angeles, CA, USA

bepartment of Neurology, University of Texas Health Sciences Center at Houston, Houston, TX, USA

'Department of Neurology, University at Buffalo, State University of New York, Buffalo, NY, USA

${ }^{\mathrm{d} D e p a r t m e n t s ~ o f ~ N e u r o l o g y ~ a n d ~ N e u r o s u r g e r y, ~ U n i v e r s i t y ~ o f ~ C i n c i n n a t i ~ M e d i-~}$ cal Center, Cincinnati, OH, USA

${ }^{\mathrm{e}}$ Corresponding Author: Ashkan Mowla, Division of Endovascular Neurosurgery, Department of Neurological Surgery, Keck School of Medicine, University of Southern California (USC), 1200 North State St., Suite 3300, Los Angeles, CA 90033, USA. Email: mowla@usc.edu

doi: https://doi.org/10.14740/jnr599 low-up brain MRI due to body size, claustrophobia, presence of metallic implants or foreign bodies, 24-h head CT was reviewed. We recorded age, admission National Institutes of Health Stroke Scale (NIHSS), discharge NIHSS, discharge modified Rankin Score (mRS), symptom onset to treatment time, clinical manifestations, discharge diagnosis and evidence of intracranial hemorrhage (ICH) on follow-up images for these patients.

A total of 637 patients received IV thrombolysis in our center during a 9.4-year period. Thirty-seven $(5.8 \%)$ were found to have no evidence of acute ischemia/infarct on their followup imaging. DWI-MRI was available for 31 patients. Mean age was $65.2 \pm 14$, mean admission NIHSS was 8 and mean discharge NIHSS was 0 . The most common symptom was leftsided hemiparesis in $45 \%$ followed by right-sided hemiparesis in $37 \%$ of those patients. Table 1 shows the clinical presentations of these 37 patients. The mean time of symptom onset to IV thrombolysis was $2.5 \mathrm{~h}$. Twenty-two (59\%) were diagnosed with TIA or averted stroke and the rest had non-vascular stroke mimics. The most common stroke mimics were migraine with aura, seizure disorder and psychogenic disorders (Fig. 1). No patient developed ICH on follow-up brain imaging or any IV r-tPA side effects such as angioedema or systemic bleeding. All patients were functionally independent on discharge, mRS 0 - 1 .

IV thrombolysis is generally safe in patients with suspected AIS who have a follow-up negative brain imaging and delaying IV r-tPA administration in cases of doubt is not appropriate. Our results support the previous findings that the use of IV r-tPA appears to be safe in stroke mimics, and prognosis is generally favorable and complications are rather infrequent [9-11]. To the

Table 1. Clinical Presentations

\begin{tabular}{lll}
\hline & $\begin{array}{l}\text { Non-vascular } \\
\text { mimics }(\mathbf{n = 1 5})\end{array}$ & $\begin{array}{l}\text { Vascular mimics } \\
(\mathbf{n = 2 2})\end{array}$ \\
\hline Left hemiparesis & $27.8 \%$ & $68.4 \%$ \\
Right hemiparesis & $55.6 \%$ & $31.6 \%$ \\
Unilateral paresthesias & $5.5 \%$ & $5.2 \%$ \\
Aphasia & $33.3 \%$ & $15.8 \%$ \\
Dysarthria & $5.5 \%$ & $21.2 \%$ \\
Unresponsiveness & $16.7 \%$ & $5.2 \%$ \\
Headache & $11.1 \%$ & $0 \%$ \\
\hline
\end{tabular}




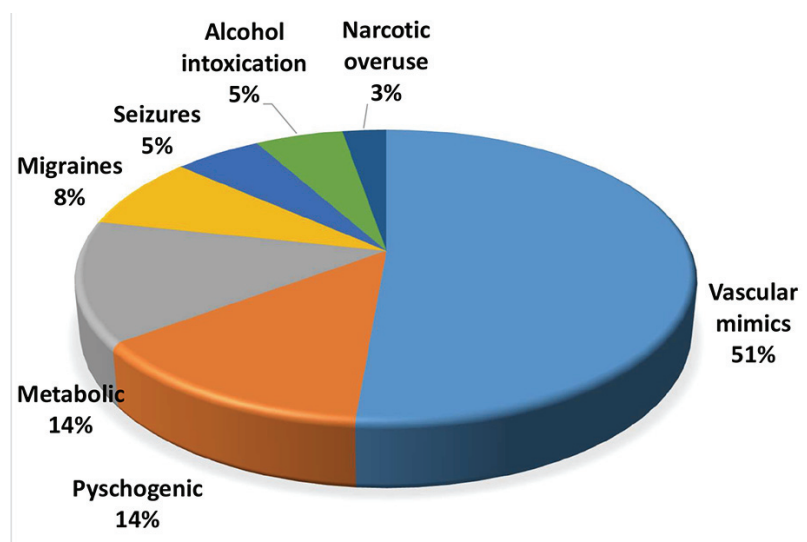

Figure 1. Etiologies of stroke mimics.

best of our knowledge, this is one of the largest reported series of patients with stroke mimics treated with IV r-tPA.

\section{Acknowledgments}

We would like to thank Ms. Deborah A. Steck, RN, MS, CNS, SCRN and Ms. Annemarie Crumlish, CCRC for their valuable and constructive guidance for our data collection.

\section{Financial Disclosure}

None to declare.

\section{Conflict of Interest}

None to declare.

\section{Informed Consent}

Not applicable.

\section{Author Contributions}

All authors have contributed to the concept, data collection, data analysis and writing of the article.

\section{Data Availability}

The authors declare that data supporting the findings of this study are available within the article.

\section{References}

1. Mowla A, Doyle J, Lail NS, Rajabzadeh-Oghaz H, Deline C, Shirani P, Ching M, et al. Delays in door-to-needle time for acute ischemic stroke in the emergency department: A comprehensive stroke center experience. J Neurol Sci. 2017;376:102-105.

2. Mowla A, Singh K, Mehla S, Ahmed MK, Shirani P, Kamal H, Krishna C, et al. Is acute reperfusion therapy safe in acute ischemic stroke patients who harbor unruptured intracranial aneurysm? Int J Stroke. 2015;10(Suppl A100):113-118.

3. National Institute of Neurological Disorders. Stroke rt, P. A. Stroke Study Group. Tissue plasminogen activator for acute ischemic stroke. N Engl J Med. 1995;333(24):15811587.

4. Singh K, Mowla A, Mehla S, Ahmed MK, Shirani P, Zimmer WE, Sawyer RN, et al. Safety of intravenous thrombolysis for acute ischemic stroke in patients with preexisting intracranial neoplasms: a case series. Int J Stroke. 2015;10(3):E29-30.

5. Mowla A, Kamal H, Lail NS, Vaughn C, Shirani P, Mehla $\mathrm{S}$, Rajabzadeh-Oghaz $\mathrm{H}$, et al. Intravenous thrombolysis for acute ischemic stroke in patients with thrombocytopenia. J Stroke Cerebrovasc Dis. 2017;26(7):14141418.

6. Kamal H, Mowla A, Farooq S, Shirani P. Recurrent ischemic stroke can happen in stroke patients very early after intravenous thrombolysis. J Neurol Sci. 2015; 358(12):496-497.

7. AbdelRazek MA, Mowla A, Hojnacki D, Zimmer W, Elsadek R, Abdelhamid N, Elsadek L, et al. Prior Asymptomatic Parenchymal Hemorrhage Does Not Increase the Risk for Intracranial Hemorrhage after Intravenous Thrombolysis. Cerebrovasc Dis. 2015; 40(5-6):201-204.

8. Rajabzadeh-Oghaz H, Varble N, Davies JM, Mowla A, Shakir HJ, Sonig A, Shallwani H, et al. Computer-Assisted Adjuncts for Aneurysmal Morphologic Assessment: Toward More Precise and Accurate Approaches. Proc SPIE Int Soc Opt Eng. 2017;10134:101341C.

9. Chernyshev OY, Martin-Schild S, Albright KC, Barreto A, Misra V, Acosta I, Grotta JC, et al. Safety of tPA in stroke mimics and neuroimaging-negative cerebral ischemia. Neurology. 2010;74(17):1340-1345.

10. Spokoyny I, Raman R, Ernstrom K, Meyer BC, Hemmen TM. Imaging negative stroke: diagnoses and outcomes in intravenous tissue plasminogen activator-treated patients. J Stroke Cerebrovasc Dis. 2014;23(5):10461050.

11. Guillan M,Alonso-Canovas A, Gonzalez-Valcarcel J, Garcia Barragan N, Garcia Caldentey J, Hernandez-Medrano I, Defelipe-Mimbrera A, et al. Stroke mimics treated with thrombolysis: further evidence on safety and distinctive clinical features. Cerebrovasc Dis. 2012;34(2):115-120. 